\title{
A SOBERANIA HOJE. PALAVRAS-CHAVE PARA UM DIÁLOGO EUROPEU LATINO-AMERICANO SOBRE UM ATRIBUTO DO ESTADO CONSTITUCIONAL MODERNO / TODAY'S SOVEREIGNTY. KEYWORDS FOR A DIALOGUE EUROPEAN/LATIN-AMERICAN ABOUT AN ATTRIBUTE OF THE MODERN CONSTITUTIONAL STATE.
}

\begin{abstract}
Markus Kotzur: Professor de Direito Internacional e Direito Europeu na Universidade de Hamburgo, Alemanha, com LL.M pela Duke University, EUA. Entre os anos de 1997-2002 foi assistente de Peter Häberle na Universidade de Bayreuth. É autor dos livros Theorieelemente des internationalen Menschenrechtsschutzes, Dunker \& Humblot, Berlin 2001 e Grenznachbarschaftliche Zusammenarbeit in Europa, Duncker \& Humblot, Berlin 2004. É Professor visitante nas Universidades de Colônia, Dresden, Würzburg, Leipzig e Münster, na Alemanha, assim como na Kaliningrad State University, na Rússia. Suas principais linhas de investigação são: Direito Constitucional Comparado, Direito Internacional, Direito Comunitário Europeu e Direito Constitucional Europeu, incluindo a dimensão histórica e filosófica da integração europeia. O presente artigo foi originalmente publicado em castelhano no livro HÄBERLE, Peter, KOTZUR, Markus. Da soberania ao direito constitucional comum: palavras-chave para um diálogo europeulatino-americano, trad. Héctor Fix-Fierro, Cuidad de México: UNAM, 2003, pp. 85-122. Os tradutores agradecem a liberalidade do Professor Doutor Markus Kotzur por autorizar a tradução e publicação deste trabalho, bem como pela atenção dispensada pelo Professor Doutor Clemens Richter, Pesquisador Associado junto ao Professor Kotzur na Universidade de Hamburgo.
\end{abstract}

Resumo: O presente artigo visa analisar a formação de comunidades políticas e questões afeitas ao conceito de soberania sob um ponto de vista histórico abordando a deontologia jurídica justificadora dos paradigmas de cada época. Discute-se, também, a proposta de implantação de uma abertura cooperativa dos Estados Constitucionais latinoamericanos, segundo o modelo europeu, a fim de reduzir desigualdades e promover a chamada soberania do ser humano.

Palavras-Chave: Comunidade Internacional, Soberania, Constitucional.

\begin{abstract}
This article aims to analyze the development of the political communities and sovereignty issues in a historical approach, focusing the juridical deontology that justifies the paradigm of every historical period. The article debates the proposal of a cooperative opening of the Latin Americans Constitutional States according to a European model, aspiring to reduce inequalities and promote the humans sovereignty.
\end{abstract}

Key-words: International Community, Sovereignty, Constitutional

Sumário: I. Introdução II. O conceito de soberania: sua dimensão histórica III. O conceito de soberania: a dimensão constitucional III.1. A soberania popular III.2. Soberania e nação IV. O conceito de soberania: a perspectiva do direito internacional IV.1. A "Soberania Parcial" da Comunidade Internacional em Matéria de Proteção dos Direitos Humanos IV.2. A ideia do contrato social mundial V. O conceito de soberania: a conjunção das perspectivas do direito constitucional e do direito internacional V.1. A soberania a serviço do ser humano V.2. Inter-relações cooperativas da soberania VI. Perspectivas e conclusão. 


\section{$\underline{\text { I. Introducão }}$}

$\mathrm{Na}$ era da globalização, o direito e a realidade da comunidade internacional atuam em todos os âmbitos do poder estatal nacional ${ }^{1}$. Isto é tão válido para a Europa como para o mundo dos Estados latino-americanos e oferece um motivo importante para um diálogo entre ambas as culturas jurídicas em matéria de "soberania". Neste sentido, a União Europeia (UE) poderia oferecer algumas palavras-chave para a discussão proveniente do rico tesouro de experiências de seu processo de integração e constitucionalização. Assim, a União Monetária Europeia, incluindo a criação de um Banco Central Europeu, é signo visível das transformações da soberania para todos os cidadãos europeus ${ }^{2}$. A soberania monetária, que originalmente era uma manifestação do Estado, converteu-se em elemento de um poder central europeu ${ }^{3}$.

A Europa em processo de se dar uma Constituição tem modificado fundamentalmente sua visão do Estado, aproximando, assim, um pouco mais o velho continente do novo mundo. Nos Estados Unidos da América, mas também na América Ibérica, a ideia de direito está muito menos referida, conceitualmente falando, ao Estado que na Europa continental. Os direitos servem em maior medida para a compensação horizontal dos interesses, e menos para expressar, em sentido vertical, dependências de poder ou relações de supra e subordinação ${ }^{4}$.

A compensação de interesses permite a publica private partnership e uma relação cooperativa entre os cidadãos e o Estado. Mas, onde se encontra em tal sistema a soberania, que tanto Thomas Hobbes como Jean Bodin situaram na origem do estado moderno ${ }^{5}$ ? Perdeu o Estado

\footnotetext{
${ }^{1}$ Veja-se a respeito Häberle, P., Europäische Verfassunglehre, 2001-2002, pp. 267 e ss., 288 e ss. et passim.

${ }^{2}$ Cfr. Hahn. J. J., Häde, U., "Europa in Wartenstand: Bemerkungen zur Währungsunion”, FS U. Everling, vol. I, 1995, pp. 381 e ss.; Pernice, I., "Das Ende der Währungspolitischen Souveränität Deutschaland und das MaastrichtUrteil der BverfG”, em ibidem, vol. II, pp. 1057 e ss,; Selmayr, M., "Aktuelle Rechtrsfragen der Wirtschafts - und Währungsunion”, em Simma, B., Schulte, C. (eds.), Völker - und Europarecht in der Aktuellen Diskussion, 1999, pp. 125 e ss.

${ }^{3}$ Winkler, G., Raum und Recht, 1999, p. 39.

${ }^{4}$ Rosenfeld, M., "Rule of Law versus Rechtsstaat", em Häberle, P., Müller, J. P., Menschenrechte und Bürgerrechte in Einer Vielgestaltigen Welt, 2000, pp. 49 e ss. ("relação antagônica entre o Estado e o Direito"; Mastronardi, Ph., "Recht und Kultur: Kulturelle Bedinhtheit und Universaler Anspruch der Juristischen Denkens", Zeitschrift für Ausländisches Öffentliches Recht und Völkerrecht, vol. 61, 2001, pp. 61 e ss., 66.

${ }^{5}$ Fabio, U. di, Das Recht Offener Staaten, 1998, pp. 16 e ss.; Oeter, S., "Souveränität - ein Überholtes Konzept?, FS H. Steinberger, 2002, pp. 259 e ss.

6 Neste sentido veja-se também Hillgruber, Ch., "Souveränität - Verteidigung Eines Rechtsbegriffs", Juristenzeitung, 2002, pp. 1072 e ss. 7
} 
completamente sua soberania, restando reduzido a simples moderador dos interesses privados? Ou a partícipe com atores não estatais, por um lado, e com espaços de cooperação e responsabilidade econômicas como a UE e o Tratado de Livre Comércio da América do Norte, por outro lado? Por acaso alguma vez o Estado possuiu uma soberania indivisa?

Quem abandona à soberania, desconhece não somente a realidade social, como também o conteúdo jurídico do conceito, assim como a simples necessidade que as comunidades políticas têm de contar com uma capacidade, competencialmente garantida, de atuação e configuração ${ }^{6}$. Quem, por outro lado, continua sustentando a habitual, mas questionável equação entre povo, Estado e nação, não é menos cego ante a realidade e frente à necessidade de dispor de uma noção de soberania que lhe seja correspondente ${ }^{7}$.

\section{O Conceito de Soberania: Sua Dimensão Histórica}

A soberania interna e externa é um dos conceitos centrais mais complexos, e ao mesmo tempo o mais debatido, da teoria do Estado e do direito internacional ${ }^{8}$. Trata-se de um conceito que, desde suas premissas, não está livre de contradições, porque formulado de maneira abstrata. A soberania circunscreve, de um lado, o "grau superlativo" de um fenômeno, seja no sentido de um conceito jurídico-normativo ou no de uma categoria sociológica ${ }^{9}$; de outro lado, se entende como princípio constitutivo da comunidade internacional, o qual pressupõe evidentemente um grau mínimo e necessário de vinculação jurídica com uma comunidade supraestatal. Uma concepção atualizada da soberania tem que ser desenvolvida a partir da rede cada vez mais complexa de vínculos supranacionais, e ao mesmo tempo, com apoio numa confirmação das raízes históricas da souveraineté.

A Antiguidade já conhecia diversas formações estatais independentes entre si, mas a ideia de soberania do Estado surgiu muito tempo depois. Os inícios se encontram na Idade Média, quando Carlos Magno associa a visão de um Império Romano renovado com uma pretensão de domínio universal, marcando com seu selo o conflitivo dualismo entre o imperador e o papa em relação à

Lerche, P., "Europäische Staatlichkeit und die Identität des Grundgezets", FS K. Redeker, 1993, pp. 131 e ss., 141, fala de "zonas flutuantes"; segue-o Fabio, U. di., Das Recht Offener Staaten, 1998, p. 94, que se refere a uma "situação flutuante" da soberania. 
questão da legitimidade do poder do Estado e da Igreja ${ }^{6}$. Junto com a distribuição de competências entre os governantes seculares e espirituais, a discussão sobre o ius ad bellum iustum, vale dizer, o poder de decisão sobre a guerra e a paz - discussão que remonta a Cícero, Santo Agostinho e São Tomás de Aquino - ofereceu um prematuro impulso ao pensamento europeu sobre a soberania. Contudo, foi apenas o jurista francês Jean Bodin (1530-1596) que, com os seus Six Livres de la République, criou o texto clássico da moderna teoria da soberania ${ }^{11}$. Sua definição da souveraineté, ou da summa potestas como in cive ac subditos legibus soluta potestas (poder sobre cidadãos e súditos não sujeito às leis), constitui a base teórica do poder soberano do Estado como poder supremo, permanente, indivisível e, em princípio, juridicamente irresponsável ${ }^{7}$. Contudo, o mesmo Bodin sublinha que, em sua concepção, a summa potestas está submetida, de um lado, ao direito divino e natural ${ }^{8}$, e por outro lado, a lex omnium gentium communis (a lei comum de todos os $\operatorname{povos}^{9}$ ), isto é, o direito internacional. A ideia de um "poder supremo" absoluto e ilimitado ${ }^{10}$, tanto internamente como em relação com outros Estados, era alheia desde o princípio à sua doutrina. $\mathrm{O}$ mesmo se pode afirmar dos teóricos do direito internacional na escolástica espanhola tardia, como Francisco de Vitoria e Francisco Suárez. Embora a soberania de um Estado lhe garanta que não esteja subordinado a uma instância de decisão ou a uma jurisdição superiores, ou mesmo a outro Estado, potencialmente mais forte ${ }^{11}$, tampouco é ilimitada, estando, pois, delimitada juridicamente e orientada ao bem da comunidade das nações ${ }^{12}$. A radicalidade da concepção hobbesiana de

\footnotetext{
${ }^{6}$ Steinberger, H., "Sovereignty", EPIL, vol. 10, 1987, pp. 397 e ss., 399; Verdross, A, Simma, B., Universelles Völkerrecht, 3 ed., 1984, p. 25. 11

Les Six Livres de la Republique, livro primeiro, capítulo VIII: "Maiestas est summa in cives ac súbditos legibus soluta potestas". A respeito, veja-se Quaritsch, H., Staat und Souveränität, vol. 1, 1970, pp. 243 e ss.; ibidem, Souveränität. Eststehung und Entwicklung des Begriffs in Frankreich und Deutschland vom 13. Jh. bis 1806, 1986, pp. 46 e ss.; Steinberger, H., "Sovereignty", EPIL, vol. 10, 1987, pp. 397 e ss., 401 e ss.

${ }^{7}$ De Republica (1601), I, 8; acerca do tema, veja-se também Wildhaber, L., "Entstehung und Aktualität der Souveränität", FS K. Eichenberger, 1982, pp. 131 e ss., 133 e ss.; Steinberger, H., "Sovereignty", EPIL, vol. 10, 1987, pp. 397 e ss., 401/402; Lindahl, H., "Sovereignty and Symbolization", Rechststheorie, vol. 28, 1997, pp. 347 e ss., 351 e ss.

${ }^{8}$ Six Livres de la Republique (1583), I, cap. IX.

${ }^{9}$ De Republica, I, 8.

${ }^{10}$ É o termo empregado por Saladin, P., Wozu noch Staaten?, 1995, S. 29.

${ }^{11}$ Cfr. a definição em Heller, H., "Die Souveränität" (1927), ibidem, Gesammelte Schriften, vol. 2, 1971, pp. 31 e ss., 65: "Chamamos soberania somente àquela unidade de decisão que não está subordinada a nenhuma outra unidade de decisão universalmente eficaz".

${ }^{12}$ A respeito, Verdross, A., Simma, B., Universelles Völkerrecht, 3 ed., 1984, p. 27; Soder, J., Die Idee der Völkergemeinschaft, 1955, pp. 95 e ss. 18

Steinberger, H., "Sovereignty”, EPIL, vol., 10, 1987, pp. 397 e ss., 400; cfr., também, Quaritsch, H., Staat und Souveränität, vol. 1, 1970, pp. 32 e ss.; Kennedy, D., “A New Stream of International Law Scholarship”, Wisconsin International Law Journal, vol. 7, 1988, pp. 1 e ss., 14 e ss.
} 
Estados sem limites no estado de natureza encontra-se demasiadamente distante do pensamento da escola de Salamanca.

A nova ordem no mundo dos Estados europeus que produziu a Paz de Westfália do ano de 1648 vinculou o pensamento sobre a soberania ao Estado territorial ${ }^{18}$, pois se atribuía à soberania, precisamente enquanto poder territorial supremo, uma função de garantia da paz e da liberdade. Dita função encontrou um importante complemento no início da proteção às minorias religiosas, proteção que, obviamente, estava limitada às confissões cristãs. Mais tardes, E. de Vattel tentou fazer uma interpretação ampla da soberania estatal e estabeleceu uma diferenciação com base nas seguintes características: autogoverno, independência de outros Estados e vinculação direta ao direito internacional ${ }^{13}$. A tríade de Vattel marcou, e marca ainda hoje, a doutrina internacional sobre a soberania, a atuação dos Estados e a jurisprudência da Corte Permanente de Justiça Internacional, primeiro, e logo depois da Corte Internacional de Justiça. Consequentemente, um Estado é soberano quando não está submetido a nenhuma outra autoridade que não seja o direito internacional, quando pode adotar decisões obrigatórias últimas sobre os seus súditos em seu território (soberania interna) e quando é independente externamente, longe de toda influencia proveniente de outros Estados ${ }^{14}$.

Com a Liga das Nações se delineou uma nova concepção da soberania, a qual conduziu à elaboração da Carta das Nações Unidas ${ }^{21}$. Nessa nova concepção, o direito à guerra é considerado um anacronismo e a ideia de um sistema de segurança coletiva assume seus contornos iniciais (Pacto Briand-Kellog de 1928). A liberté de guerre, até esse momento um atributo destacado da soberania, deixa de existir. Um salto evolutivo igualmente grande marca as instituições supranacionais e outras de caráter interestatal, as quais conduzem a uma relativização mais ou menos marcada da soberania. Em primeiro lugar há de se mencionar a UE, mas também a Organização para a Cooperação e o Desenvolvimento Econômicos (OCDE), com suas redes informativas e institucionais ${ }^{15}$, ou o TLCAN $^{\text {N.T.1 }}$. A cadeia de exemplos poderia se multiplicar.

\footnotetext{
${ }^{13}$ Verdross, A., Simma, B., Universelles Völkerrecht, 3 ed., 1984, p. 28.

${ }^{14}$ Cfr. Heller, H., "Die Souveränität" (1927), ibidem, Gesammelte Schriften, vol. 2, 1971, pp. 31 e ss., 141 (unidade universal de decisão territorial interna e externamente); Verdross, , A., Simma, B., Universelles Völkerrecht, 3 ed., 1984, p. 29 e ss. 21

A respeito, consulte-se Steinberger, H., "Sovereignty”, EPIL, vol. 10, 1987, pp. 397 e ss., 408.

${ }^{15}$ Sobre o tema, Senghaas, D., "Weltinnenpolitik - Ansätze für Ein Konzept”, Europaarchiv, 1992, pp. 643 e ss.; mais exemplos em Macorquodale, R., Fairbrother, R., "Globalization and Human Rights", Human Rights Quarterly, vol. 21, 1999, pp. 735 e ss.; 753 e ss. (acordos multilaterais sobre investimentos, Fundo Monetário Internacional etc.). N.T.1

Tratado de Livre Comércio da América do Norte, ou NAFTA - North American Free Trade Agreement.
} 
Esta retrospectiva histórica fragmentada nos conduz às primeiras conclusões. Uma vez que a ideia de soberania surgiu na história, seria estéril qualquer consideração a-histórica e alheia à realidade, pois a soberania está sujeita à evolução e à mudança, e por isso deve ser delineada a sua pretensão de validade e reconhecidos os seus limites na realidade do mundo atual dos Estados ${ }^{16}$. Ademais, existe um telos imanente ao pensamento sobre a soberania que se opõe a qualquer absolutização unilateral. A soberania está sempre ligada à questão da fundamentação da competência e é, em tal medida, uma noção ordenadora que assegura a paz e a liberdade. $O$ conceito não representou nunca, nem o representa agora, somente um predicado da dominação, e por isso não pode ser reduzido à "independência" e ao "poder absoluto".

\section{O Conceito de Soberania: A Dimensão Constitucional}

\section{III.1. A Soberania Popular}

O livre poder de configuração de um povo ou nação forma parte, sem dúvida, das peças centrais do pensamento sobre a soberania no Estado Constitucional ${ }^{24}$. Contudo, isso pressupõe um vinculo necessário entre a soberania e um povo mais ou menos homogêneo? No Estado Constitucional democrático, somente o demos pode ser o titular do poder soberano do Estado? Ou sua "capacidade de decisão" independente está limitada, desde logo, pelas interações supraestatais das mais diversas formas de unificação política? Que papel desempenha a diversidade de opiniões, interesses e valores individuais que se escondem detrás da magnitude abstrata do "povo"? ${ }^{17}$

A associação entre povo e Estado como ordem concreta que se sustenta na decisão soberana daquele constitui a peça central da legitimação democrática. J. J. Rousseau cunhou nesse sentido o conceito clássico de soberania popular ${ }^{26}$. Dito conceito pressupõe o povo, sem determinar quem o seja, e tampouco as dependências de natureza fática, jurídica e ético-moral nas quais vive. Através da refinada teoria da legitimidade de dupla categoria que elaborou o abade Sieyés, graças à distinção entre pouvoir constituant e pouvoir constitué, converte-se o povo em "fundamento

\footnotetext{
${ }^{16}$ Cfr. Lhotta, R., "Der Staat als Wille und Vorstellung”, Der Staat, vol. 36, 1997, pp. 189 e ss., 197; Lindhal, H., "Sovereignty and Symbolization", Rechtstheorie, vol. 28, 1997, pp. 347 e ss., 347: "sovereignty as a 'historical' category". 24

Hilgruber, Ch., "Souveränität - Verteidigung Eines Rechtsbegriffs", Juristenzeitung, 2002, pp. 1072 e ss.

${ }^{17}$ Cfr. Simson, W. v., "Was heißt in Einer Europäischen Verfassung 'Das Volk'?”, EuR, 1991, pp. 1 e ss., 2.
} 
originário" dos atos soberanos constituintes, de natureza supraconstitucional e presumidamente ilimitada, dos quais derivam sua legitimidade todos os atos de autoridade sujeitos à Constituição ${ }^{27}$.

Mas aqui coincidem estreitamente uma verdade profunda e um mal-entendido fundamental. Somente é legítimo o Estado que se funda na soberania popular, tanto a constituinte como a legislativa, o que torna possível, através das normas jurídicas, a formação da vontade política do povo, sujeitando o seu poder ao controle democrático. No entanto, a decisão livre, sem limites, do povo é uma ficção perigosa. Já a Declaração Francesa dos Direitos do Homem e do Cidadão sabia que não podem existir decisões constituintes sem pressupostos, pois se bem proclamam os artigos $3^{\text {oN.T.2 }}$ e $6^{\text {oN.T.3 }}$ a plena soberania da nação, a qual se traduz na volunté générale das leis, também assinala que os direitos inalienáveis do homem, que estão subtraídos à arbitrariedade estatal e à decisão do povo, constituem o fim de toda associação política (artigo $2^{\circ}$ N.T.4)28.

26

Veja-se a respeito, Böckenförde, E.-W., "Demokratie als Verfassungsprinzip", HStR, vol. 1, 2 ed., 1995, §22, n.m. 3; Beutler, B., "Offene Staatlichkeit und Europäische Integration", FS E.-W. Böckenförde, 1995, pp. 109 e ss., 114; Schmidt-Aßmann, E., Das Allgemeine Verwaltungsrecht als Ordnungsidee, 1998, pp. 81 e ss.

27

Sobre o tema, Thiele, U., "Verfassungsgebend Volkssouveränität und Verfassungsgerichtsbarkeit”, Der Staat, vol. 39, 2000, pp. 397 e ss., 391; Möllers, Ch., "Globalisierte Jurisprudenz Einflüsse Relativierter

Nationalstaatlichkeit auf das Konzept des Rechts und die Funktion Seiner Theorie", Archiv für Rechts- und Sozialphilosophie, n. especial 79, 2001, pp. 41 e ss., 44. No contexto do atual debate sobre a Constituição Européia, veja-se Buhner, R., "Gott und dir Fürsten Sind aus dem Spiel”, Frankfurter Allgemeine Zeitung de 27 de outubro de 2001, Bilder und Zeiten, p. 1. N.T.2

“Artigo $3^{\circ}$ - O princípio de toda a soberania reside essencialmente na Nação. Nenhuma corporação, nenhum indivíduo pode exercer autoridade que aquela não emane expressamente." N.T.3

“Artigo 6- A Lei é a expressão da vontade geral. Todos os cidadãos têm o direito de concorrer, pessoalmente ou através dos seus representantes, para a sua formação. Ela deve ser a mesma para todos, quer se destine a proteger quer a punir. Todos os cidadãos são iguais a seus olhos, são igualmente admissíveis a todas as dignidades, lugares e empregos públicos, segundo a sua capacidade, e sem outra distinção que não seja a das suas virtudes e dos seus talentos." N.T.4

"Artigo $2^{\circ}$ - O fim de toda a associação política é a conservação dos direitos naturais e imprescritíveis do homem. Esses Direitos são a liberdade. a propriedade, a segurança e a resistência à opressão.” 28

Böckenförde, E.-W., "Demokratie als Verfassungsprinzip”, HStR, vol. 1, 2 ed., 1995, §22, n.m. 3; sobre a soberania limitada veja-se também Kirchhof, P., "Der Demokratische Rechsstaat - die Staatsform der Zugehörigen”, HStR, vol. IX, 1997, § 221, n.m. 8.

J. Isensee soluciona esta tensão por meio da ideia da "nação fundada nos direitos humanos" rompendo assim a exclusão que sugere o nacional ${ }^{30}$. A formação de uma unidade política possui

\footnotetext{
${ }^{18}$ Isensee, J., "Die Alte Frage Nach der Rechtfertigung der Staates”, Juristenzeitung, 1999, pp. 265 e ss., 277, sobre a problemática da "nação fechada", veja-se Grabitz, E., Europäisches Bürgerrecht Zwischen Marktbürgerschaft und Staatsbürgerschaft, 1970, pp. 25 e ss. 30
} 
numerosos pontos de referência, o mais amplo dos quais se encontra na premissa antropológica da dignidade humana ${ }^{19}$; muitos outros de natureza concreta radicam na cultura e na história, nas necessidades e nos interesses de liberdade e segurança vividos cotidianamente. O Estado nacional é o espaço familiar para reuni-los, mas não o único. Uma razão de que se absolutize essa familiaridade pode ser encontrada na concepção da soberania popular como tal. Este elemento essencial e indiscutível, com razão, do Estado Constitucional moderno, implica de certo modo, sob a forma de um "efeito secundário" indesejado, a equivalência conceitual de Estado e povo no "povo do Estado", determinado pela relação jurídica da nacionalidade ${ }^{32}$. "Povo do Estado" converte-se mais numa tautologia do que numa declaração da tensão que existe na relação entre demos e ethnos ${ }^{20}$.

No entanto, povo e Estado não são idênticos. O Estado é uma concretização do povo e de seu papel no exercício das funções estatais, pois é um modelo de ordem que permite ao povo atuar politicamente ${ }^{21}$. O conceito de povo de caráter puramente jurídico que se reduz ao pertencimento estatutário a uma organização de dominação estatal continua sendo insatisfatório para qualificar o sujeito ao qual se atribuem as decisões soberanas. O que melhor legitima a soberania do povo é a capacidade de produzir uma vontade de maneira livre, sem coação ${ }^{22}$. Por trás da ideia da soberania popular se encontra um motivo fundamental antimonárquico e antiabsolutista, que é a livre autodeterminação do indivíduo ${ }^{36}$. A soberania popular transforma-se assim na "soberania cidadã $" 37$. A res publica, à qual pertencem os cidadãos, os quais a convertem em sua "coisa pública" originária, adquire realidade tanto nos Estados Constitucionais como nos fenômenos supraestatais.

\section{III.2. Soberania e Nacão}

\footnotetext{
O poder constituinte do povo, presumidamente autônomo, se choca com numerosos limites heterônomos, de tipo jurídico, mas também pré-jurídico e meta-jurídico: a vinculação ao direito internacional; a vinculação aos direitos das comunidades regionais, como a UE, o Conselho da Europa, a Convenção Européia de Direitos Humanos ou a Organização para a Segurança e a Cooperação na Europa.

${ }^{19}$ Häberle, P. "Die Menschenwürde als Grundlage der Staatlichen Gemeinschaft", HStR, vol. 1, 2 ed., 1995, pp. 815 e ss. 32

Grawert, R., "Staatsvolf und Staatsangehörigkeit”, HStR, vol. 1, 2 ed., 1995, §14, pp. 663 e ss.; Böckenförde, E.W., "Demokratie als Verfassungprinzip", HStR, vol. 1, 2 ed., 1995, § 22, n.m. 26.

${ }^{20}$ Sobre a relação entre demos e ethnos, cfr. Broekman, J. M., A Philosophy of European Union Law, 1999, p. 281.

${ }^{21}$ Simson, W. v., “Was Heißt in Einer Europäischen Verfassung 'Das Volk'?”, EuR, 1991, pp. 1 e ss., 8.

${ }^{22}$ Ibidem, p. 3.36

Steinberger, H., "Der Verfassungsstaats als Glied Einer Europäischen Gemeinschaft", VVDStRL, vol. 50, 1991, pp. 9 e ss., 23.
} 
Quando o demos subsiste como cifra demasiadamente abstrata da unidade e da pluralidade que se encontram detrás do "soberano", outras são as magnitudes que entram em jogo. A cultura e a língua comuns, em suma, o laço que unifica a nação que despertou para a autoconsciência política, converte a esta em titular legítimo do poder de decisão soberana. Nação e povo do Estado formam uma simbiose no pensamento político do Estado nacional (alemão). A nação encontra uma manifestação visível na metáfora do povo do Estado como comunidade pessoal de destino (pré)político, caracterizada pela origem, pela língua e pela história comuns, e indissociavelmente ligada à existência de seu Estado ${ }^{38}$. Assim, não somente se tornam inseparáveis povo e soberania, como também nação e soberania. Exemplos muito diversos confirmam esta conexão. Não é nenhuma causalidade que o Tratado de Amsterdã, ao invocar a "identidade nacional" (artigo $6^{\circ}$, inciso 3, do Tratado da União Europeia ${ }^{\text {N.T.5 }}$ ), trate de prevenir um mal-estar amplamente difundido, não somente na Alemanha, que se atribui à insidiosa erosão da soberania nacional, e ao faze-lo estabeleça implicitamente a equivalência entre perda de soberania e perda de identidade ${ }^{39}$.

A nova Constituição Federal Suíça, por sua vez, e seguindo o projeto do Conselho Federal, se absteve de empregar o termo "nação suíça". Nos debates constituintes esta questão quase não foi discutida, mas na campanha anterior ao referendo obrigatório foi enfaticamente denunciada pelo grupo nacional-conservador como uma "traição a Suíça". A indignação pode ser entendida por quem conscientemente leva em consideração a conexão específica que, para a

\footnotetext{
37 Häberle, P., Europäische Verfassungslehre, 2001-2002, p. 355: "Não se esqueça que o povo é antes de tudo uma união de cidadãos. A democracia é o "governo dos cidadãos", não o do povo no sentido rousseauniano" (ênfase no original). 38

BverfGE 83,37 (40, 50 e ss.)); Böckenförde, E.-W., "Demokratie als Verfassungprinzip", HStR, vol. 1, 2 ed., 1995, § 22, n.m. 26.

Hailbronner, H., “Aufgabe von Souveränitätsrechten als EU-Mitglied Deutsche Erfahrungen”, FS H. Maurer, 2001, pp. 97 e ss., 101; Doehring, K., "Die Nationale 'Identität' der Mitgliedstaaten der Europäischen Union”, FS U. Everling, vol. I, 1995, pp. 263 e ss., 271, tem medo de que uma completa supraordenação por parte do direito comunitário tenha por resultado uma "identidade coxa".

Suíça, existe entre nação e soberania. Em vista de sua heterogeneidade linguística e cultural, a "nação suíça” está marcada, sobretudo, pelos atributos de seu Estado soberano, em cuja cúspide se encontra a democracia semidireta que lhes outorga identidade. ${ }^{23}$
}

\footnotetext{
${ }^{23}$ Hangartner, Y., "Schweizerische Nation und Europäische Integration”, FS H. Maurer, 2001, pp. 949 e ss.
} 
Um terceiro exemplo: em suas sentenças sobre os tratados com a RDA (1972) e de Maastricht (1993), o Tribunal Constitucional Federal alemão menciona o conceito de soberania junto com o de povo e nação ${ }^{24}$. O elemento que liga as três categorias é a já citada metáfora da "comunidade pessoal de destino". O povo, enquanto nação, é o objeto passivo de um destino comum, mas também um sujeito que ativamente configura o seu destino político. Ainda que possa parecer paradoxal, a ideia da comunidade de destino é um modelo de interpretação da nação e, ao mesmo tempo, aponta para mais além dela, vale dizer, é de caráter supraestatal já em suas raízes. É certo que o elemento da "fatalidade" encobre o fato de que o Estado e a comunidade de cidadãos não estão dados de maneira natural, mas sim que adquirem sua identidade coletiva somente através dos processos democráticos, mas o topos remete efetivamente às camadas profundas, materiais e culturais, que dito devir pressupõe. Entretanto, assim entendido, o destino não é um fenômeno nacional, mas algo que descreve qualquer forma de comunidade cultural humana. $\mathrm{O}$ experimentar $\mathrm{e}$ padecer perigos em comum, assim como as ações para afasta-los, não se restringe à nação. O que se espera do Estado nacional em termos de garantia da liberdade, de promoção da paz, de busca existencial e de prevenção de riscos, não tem sido confiado à nação, mas sim à comunidade democrática como unidade de ação

institucionalizada, constitucionalizada e aberta aos espaços de responsabilidades supraestatais ${ }^{42}$.

\section{O Conceito de Soberania: A Perspectiva do Direito Internacional}

\section{$\underline{\text { IV.1. A "Soberania Parcial” da Comunidade Internacional em Matéria de Protecão }}$}

\section{dos Direitos Humanos}

Um importante deslocamento dos acentos em matéria de soberania, sob a perspectiva do direito internacional, deve-se à proteção universal dos direitos humanos. Pense-se somente na discussão sobre a legitimidade da intervenção humanitária, na guerra do Kosovo, na luta contra o terrorismo

\footnotetext{
${ }^{24}$ BverfGe 36, 1 (19, 31) Decisão sobre o Tratado com a RDA; e 89, 155 (182 e ss.) Sentença sobre o Tatrado de Maastricht; a respeito Grawert, R., "Der Deutschen Supranationaler Nationalstaat”, FS E.-W. Böckenförde, 1995, pp. 125 e ss., 137; Pernice, I., "Carl Schmitt, Rudolf Smend und die Europäische Integration”, Archiv des Öffentlichen Rechts, vol. 120, 1995, pp. 100 e ss. 42

Heller, H., Staatlehre, 6 ed., 1983, pp. 228 e ss; toma-o como ponto de partida Grawert, R., "Der Deutschen Supranationaler Nationalstaat", FS E.-W. Böckenförde, 1995, pp. 125 e ss., 135.
} 
internacional, no fim do regime talibã no Afeganistão, ou no latente conflito atual com o Iraque. Em vista da multiplicidade de exemplos, bastarão breves palavras-chave para a clarificação teórica.

No mundo globalizado do século XXI não somente os estados, como também os indivíduos e os grupos sociais, encontram-se inseridos numa complexa rede de relações multinacionais. Ainda que não se faça supérflua, a relação, o genuine link, entre os nacionais e o "seu" Estado, se relativiza ${ }^{25}$. Assim como não se pode conceber a Constituição com referência exclusiva ao Estado, tampouco a soberania é de origem estatal. São a Constituição e a rede de ordenamentos constitucionais nos quais todo Estado está inserido que criam os fundamentos da soberania. É por isso que a comunidade internacional dos Estados possui um amplo fragmento de soberania em matéria de direitos humanos, junto com o Estado nacional soberano. Dita comunidade possui um poder de definição e uma competência de atuação originária em face dessa ordem constitucional parcial. $\mathrm{O}$ cumprimento efetivo é, naturalmente, uma questão à parte. Se ela mesma é parcialmente soberana em matéria de direitos humanos, então a comunidade dos Estados deve estar disposta a assumir a proteção dessas liberdades e desses direitos aí onde fracasse o Estado constitucional nacional. Disso dá conta a local remedies rule nos pactos internacionais de direitos humanos, que pretende não somente desafogar as instâncias supranacionais, como também fixar que a competência preeminente dos tribunais nacionais é uma expressão da subsidiariedade. A decisão que afeta diretamente ao cidadão deve ser tomada em nível local. Somente quando se tiver esgotado, no caso concreto, a via judicial interna e, seja qual for a razão, não se tenha outorgado proteção jurídica suficiente, se estabelecerá a competência da instância internacional. Assim, neste âmbito, a comunidade das nações convertese em titular de decisões parcialmente soberanas a serviço do ser humano.

A soberania é uma ideia ordenadora necessária à convivência internacional, e que foi positivada no artigo $2^{\circ}, 1$ da Carta das Nações Unidas ${ }^{\text {N.T.6 }}$, e que ainda é irrenunciável na era das relações supraestatais. Contudo, enquanto fonte de justificação, não está dada de antemão de maneira natural, não é um fim em si mesma e não é absoluta, assim como tampouco a liberdade também jamais poderá ser absoluta ${ }^{44}$.

\footnotetext{
${ }^{25}$ Cfr. Nicolaysen, G., "Der Nationalstaat Klassischer Prägung Hat Sich Überlebt”, FS U. Everling, vol. II, 1995, pp. 945 e ss., 945.
} 


\section{IV.2. A Ideia do Contrato Social Mundial}

A ideia de um contrato social mundial relativiza igualmente o pensamento tradicional da soberania. Suas raízes históricas remontam à civitas maxima de Christian Wolff: uma humanidade constituída por um quase-contrato, uma sociedade da humanidade constituída através de direitos e obrigações humanos ${ }^{45}$. A teoria clássica do direito internacional, orientada pelo consenso, entende a soberania, em contrapartida, como fundamento determinante da convivência entre os Estados e concebe a ordem internacional recorrendo à doutrina do contrat social como contrato social entre Estados soberanos ${ }^{46}$. Um exemplo tangível na realidade histórica de semelhante contrato, com frequência ficticiamente imaginado, é a Paz de Westfália, a qual legitima ao mesmo tempo a existência de uma comunidade soberana europeia de Estados e tem sua própria legitimação derivada novamente da doutrina do poder soberano dos Estados contratantes ${ }^{47}$.

Contudo, esta fundamentação conserva em si uma contradição de peso, pois o Estado cria primeiro seu status de soberano, para logo após remeter-se precisamente a ele como fonte legitimadora de sua atuação ${ }^{48}$. Mais ainda, em analogia com o contrato social clássico, os Estados

N.T.6

“Artigo 2 - A Organização e seus Membros, para a realização dos propósitos mencionados nos Artigo 1, agirão de acordo com o seguintes Princípios: 1. A Organização é baseada no princípio da igualdade de todos os seus Membros $[\ldots] " .44$

Veja-se também a crítica em Purvis, N., "Critical Legal Studies in Public International Law”, Harvard International Law Journal, vol. 32, 1991, pp. 81 e ss., 100.

45

Wolff, C., Jus Naturae, VII, §142; sobre o tema Cheneval, F., "Der präsumtiv Konsens der Menschen und Völker Christian Wolffs Theorie der Civitas Maxima”, Archiv für Rechts- und Sozialphilosophie, vol. 85, 1999, pp. 563 e ss., 572. 46

Purvis, N., "Critical Legal Studies in Public International Law", Harvard International Law Journal, vol. 32, 1991, vol. 81 e ss., 93; cfr. também Pieper, S. U., "'The Clash of Civilization' und das Völkerrecht”, Rechtstheorie, vol. 29, 1998, pp. 331 e ss., 339 e ss. 47

Cfr. Koskenniemi, M., "From Apology to Utopia, 1989, p. 73; Purvis, N., "Critical Legal Studies in Public International Law”, Harvard International Law Journal, vol. 32, 1991, pp. 81 e ss., 97.

48

Ibidem; Kennedy, D., “A New Stream of International Law Scholarship”, Wisconsin International Law Journal, vol. 7, 1988, pp. 1 e ss., 30 e ss.

são equiparados aos indivíduos, e as relações entre eles são descritas como se se tratasse de relações entre indivíduos. A soberania dos Estados é tratada como conceito paralelo à liberdade dos indivíduos $^{26}$, a saber, como a vontade livre dos Estados, a qual não pode ser limitada por outra

\footnotetext{
${ }^{26}$ Sobre o tema, Koskenniemi, M., “From Apology to Utopia, 1989, pp. 68 e ss., e 262 e ss.
} 
coisa que não o consenso entre eles $^{27}$. Sem dúvida, isto dá suporte à ideia da personalidade unitária do Estado, uma imagem antropomorfa do Estado no sentido de que falara Jellinek ${ }^{28}$. Consequentemente, a uma vontade estatal unitária corresponderia uma formação unitária da vontade estatal $^{29}$. A proximidade com a imagem do governante soberano, que personifica o Estado absolutista, não é acidental ${ }^{30}$. Um conceito de soberania de tal modo situado no Estado personificado oculta, em última instância, a diversidade pluralista de todos os que constituem a esse Estado. Assim como o Estado se origina na diversidade pluralista, a comunidade internacional não vive somente da vontade dos Estados soberanos, mas sim que nela participam todas as forças sociais, desde as associações econômicas, passando pelos meios de comunicação, até os indivíduos. São estas forças que, assumindo sua responsabilidade em termos de bem comum em face das gerações presentes e futuras, têm que configurar de maneira sempre renovada a sua comunidade. A imagem do "contrato social mundial" caracteriza este processo de maneira muito mais adequada que todas as teorias sobre a vontade do Estado.

\section{O Conceito de Soberania: A Conjunção das Perspectivas do Direito}

\section{Constitucional e do Direito Internacional}

\section{V.1. A Soberania a Servico do Ser Humano}

As pretensões de aproximação ao conceito de soberania a partir das perspectivas do direito constitucional e do direito internacional, que apresentamos primeiro de forma separada, devem agora ser reunidas. Isso permite notar o ponto de referência comum, e mais profundo, de ambas as dimensões: o ser humano que deseja viver em liberdade numa ordem constitucional. Somente uma concepção instrumental da soberania, a serviço do ser humano, pode justificar qualquer forma de exercício do poder. Soberania não quer significar poder absoluto do monarca, assim como

\footnotetext{
${ }^{27}$ Franck, Th., "Legitimacy in the International System”, American Journal of International Law, vol. 82, 1988, pp. 705 e ss., 759; consulte-se também Grabitz, E., Freiheit und Verfassunsrecht, 1976, p. 166.

${ }^{28}$ Veja-se Heller, H., "Die Souveränität" (1927), ibidem, Gesammelte Schriften, vol. 2, 1971, pp. 31 e ss., 120;

Grabitz, E., Freiheit und Verfassungsrecht, 1976, p. 177. cfr. também Tsatsos, D., "Die Europäische Uniongrundordnung", EuGRZ, 1995, pp. 287 e ss., 290; von Unruh, G.-C., "Grundgedankem zur Entwicklung des Neuzeitlichen Verfassungsstaates", BayVBl., 1999, pp. 11 e ss., 13.

${ }^{29}$ Cfr. Heller, H., "Die Souveränität" (1927), ibidem, Gesammelte Schriften, vol. 2, 1971, pp. 31 e ss., 63; sobre o tema Hebeisen, M. W., Souveränität in Frage Gestellt, 1995, pp. 455 e ss.

${ }^{30}$ Preuß, H., Gemeinde, Staat, Reich, 1899, p. 105.
} 
tampouco se refere ao mito do poder originário e ilimitado de um povo presumidamente homogêneo, mas sim que se funda na autodeterminação do indivíduo como elemento central de sua dignidade humana e de seu papel como cidadão ativo no Estado constitucional e na comunidade política que o sustém ${ }^{54}$. A carreira mundial que tem feito o conceito europeu-norte-americano de Constituição depois das revoluções norte-americana e francesa tem sua raiz na ideia de que a Constituição em si promete instituir a autodeterminação soberana do ser humano ${ }^{55}$. A autodeterminação do indivíduo converteu-se em elemento constitutivo do conceito pósrevolucionário e do conceito moderno de soberania.

Assim como o Estado existe para o homem e ao mesmo tempo tem que ser interpretado de maneira "humana" e "alusiva à humanidade" ${ }^{56}$, a soberania se legitima a partir da garantia da liberdade humana, para a qual se requer um Poder Legislativo, um Poder Executivo e um Poder Judiciário que sejam eficazes ${ }^{57}$. O Estado é uma "forma de realização da liberdade" ${ }^{\text {; }}$; seu monopólio da violência e da aplicação do direito torna efetiva a proteção dos direitos humanos ${ }^{59}$. Mas o Estado também está vinculado às garantias supraestatais dos direitos humanos, contra as quais já não pode alegar, como escudo, a soberania. Os pactos internacionais de direitos

54

Nesse sentido Pernice, I., "Europäische und Nationales Verfassungsrechts", VVDStRL, vol. 60, 2001, pp. 148 e ss., 162; cfr. Oeter, S., "Souveränität ein Überholtes Konzept?", FS. H. Steinberger, 2002, pp. 259 e ss.

55

Hofmann, H., "Von der Staatssoziologie zu einer Soziologie der Verfassung", Juristenzeitung, 1999, pp. 1065 e ss: "O que fascinou aos seres humanos foi o sentimento positivo de converterem-se em donos dos seus próprios destinos em um sentido pleno através de uma Constituição, cada um para si e todos juntos...”. Remetemos, também, para Schuppert, G. F., "Überlegungenzur Demokratischen Legitimation des Europäischen Regierungssystems", FS D. Rauschning, 2001, pp. 201 e ss., 204; Peters, A., Elemente einer Theorie der Verfassung Europas, 2001, pp. 95 e ss. 56

Heller, H., Staatslehre, 6 ed., 1983, p. 36. 57

Sobre o tema Hennis, W., Das Problem der Souveränität, 1951, p. 37. 58

Pauly, W., "Hegel und die Frage Nach dem Staat", Der Staat, vol. 39, 2000, pp. 381 e ss., 395.

Krüger, H., Allgemeine Staatslehre, 1966, p. 528: "Portanto, o Estado não é o oposto nem o rival do direito e da liberdade, mais sua realidade e o seu pressuposto". Pernthaler, P., "Grundrechtsdogmatik und Allgemeine Staatslehre", FS F. Ermacora, 1988, pp. 605 e ss., 606; Brugger, W., "Menschenrechte im Modernen Staat", Archiv des Öffentlichen Rechts, vol. 114, 1989, pp. 537 e ss., e 557; Hofmann, H., "Menschenrechtliche Autonomieansprüche", Juristenzeitung, 1992, pp. 165 e ss., e 170 e ss.; ibidem, "Geschichtlichkeit und

Universalitätsanspruch des Rechtsstaats”, Der Staat, vol. 34, 1995, pp. 1 e ss.; Schreckenberger, W., "Der Moderne Verfassungsstaat und die Idee der Weltgemeinschaft”, Der Staat, vol. 34, 1995, pp. 503 e ss., 509; Isensee, J., "Die Alte Frage Nach der Rechtfertigung des Staates", Juristenzeitung, 1999, pp. 265 e ss., 270; Schneider, H.-P,. "50 Jahre Grundgesetz", Neue Juristisches Wochenschrift, 1999, pp. 1497 e ss., 1499; Denninger, E., "Die Wirksamkeit der Menschenrechte in der Deutschen Verfassungsrechtsprechung”, Juristenzeitung, 1998, pp. 1129 e ss., 1129.

humanos, os convênios regionais como o são as convenções europeia e americana de direitos humanos, e mais recentemente, a Carta de Direitos Fundamentais da União Europeia concretizam 
melhor o mandado soberano do Estado. A partir dos direitos humanos, a soberania não tem sido definida, nem o está agora, pelo poder ilimitado do Estado. Os próprios direitos humanos dão direção às margens de ação e aos poderes de atuação das unidades políticas constituías em nível estatal e supraestatal. O presidente tcheco, V. Havel encontrou uma fórmula para isso:

A soberania do município, da região, do povo, do Estado, qualquer soberania superior, somente tem sentido quando provenham da que, de fato, é a única soberania originária, a saber, a soberania do ser humano, a qual tem a sua expressão política na soberania do cidadão. ${ }^{31}$

\section{V.2. Inter-relações Cooperativas da Soberania}

O direito constitucional e o direito internacional ilustram, precisamente através das suas múltiplas inter-relações, a realidade do Estado constitucional aberto e cooperativo ${ }^{32}$. O modelo cooperativo conduz, em última instância, às inter-relações cooperativas da soberania ${ }^{62}$. Já Rudolf Smend havia descrito as relações entre os Estados como relações de "intercâmbio e de vida espiritual, vale dizer, de configuração recíproca e autoconfiguração"33.

Quanto mais intensivamente se ver o moderno Estado previdência na incapacidade de sozinho satisfazer as suas tarefas e quanto mais tiver de recorrer à cooperação com outros Estados, tanto mais precária se torna a brecha entre as obrigações comunitárias fáticas e a doutrina da autarquia soberana. O campo da economia oferece um exemplo disso. Dependente da cooperação, o Estado possui quando muito a "posição de contraforte de eficácia regional frente aos processos do tráfego global"; converte-se em "centro de condensação regional na estrutura das constelações de poder supraestatais" ${ }^{34}$. Sua singularidade, exclusividade e posição monopólica pertencem ao passado. Se a alternativa para o Estado nacional é, por exemplo, tomar medidas de política econômica ou de proteção ambiental somente mediante a cooperação entre Estados, ou não o puder

\footnotetext{
${ }^{31}$ Havel. V., "Die Herrschaft der Gesetze”, em ibidem, Sommermeditationen, 2 ed., 1994, pp. 14 e ss., 27.

${ }^{32}$ Häberle, P. "Der Kooperative Verfassungsstaat" (1978), em ibidem, Verfassung als Öffentlicher Proze $\beta, 3$ ed., 1998, pp. 407 e ss. 62

Sobre o problema da "atribuição de responsabilidade em redes de cooperação", veja-se Fabio, U. di., Das Recht Offener Staaten, 1998, pp. 126 e ss.

${ }^{33}$ Smend, R., "Verfassung und Verfassungsrecht, 1928, p. 65.

${ }^{34}$ Grawert, R., "Der Deutschen Supranationaler Nationalstaat", FS E.-W. Böckenförde, 1995, pp. 125 e ss., 142; sobre o crescimento e a transformação das funções da administração Mayntz, R., Soziologie der Öffentlichen Verwaltung, 4 ed., 1997, pp. 45 e ss.
} 
fazê-lo em absoluto, então toda forma de associação nestas matérias é ${ }^{35}$ mais que um simples ato de garantia da soberania.

No interior do Estado apresenta-se também um fenômeno paralelo. Se o Estado não se abre à cooperação com a sociedade civil, perde também aqui um pedaço de sua "soberania", entendida como poder soberano de configuração. A unidade pessoal do Estado, sua soberania, como é chamada na tradição monárquica, se transforma
no interior e no exterior. As mesmas forças funcionais da sociedade industrialburocrática, que
impeliam no interior em direção da sociedade em grupos, em direção ao pluralismo e em direção à
remodelação compatível com este das instituições do direito estatal, conduzem externamente em
direção a novas uniões, que condensam as instituições entre os Estados

em instituições supraestatais.

O aspecto cooperativo tem consequências imperativas. "No conceito jurídico-estatal de soberania tem que estar contido o fato da coordenação e conjunção dos Estados como momento material, de tal modo, que seus limites estejam definidos pelo valor próprio do ser humano" ${ }^{\text {"36 }}$. Dito de outro modo: o conceito material de soberania se apoia numa dupla premissa. Tal qual o

Estado Constitucional, funda-se na dignidade humana e no valor próprio da pessoa como "premissa antropológica" ${ }^{37}$, contendo, no entanto, ao mesmo tempo, a dimensão da cooperação, já que o estado contemporâneo não se caracteriza tanto pela sua magnitude abstrata, e sim pela pluralidade de suas vinculações jurídicas e fáticas ${ }^{38}$. Se a soberania foi, historicamente falando, resultado da concentração de poder nas mãos do soberano ${ }^{39}$, e se foi dessa forma que adquiriu seus conteúdos para depois, gradualmente, ser acolhida pelo Estado Constitucional, então, hoje em dia, é

\footnotetext{
${ }^{35}$ Bülck, H., "Der Strukturwandel der Internationalen Verwaltung”, Recht und Staat in Geschichte und Gegenwart, $\mathrm{n}$. 247, 1962, p. 23.

${ }^{36}$ Hennis, W., Das Problem der Souveränität, 1951, p. 131. Fazemos referência também à tensão entre a Lei Fundamental e o poder público exercido pela comunidade internacional dos Estados, a qual foi pela primeira vez tema do congresso de professores alemães de direito do Estado em 1959. Erler, G., "Das Grundgezetz und die Öffentliche Gewalt Internationaler Staatengemeinschaften”, VVDStRL, vol. 18, 1960, pp. 7 e ss., percebe com razão que "o princípio da clausura e exclusividade do poder estatal" se põe em intersição pela "possibilidade do exercício, no território federal, de um poder público... que não tem sua origem no poder do Estado alemão".

${ }^{37}$ Häberle, P., "Die Menschenwürde als Grundlage der Staatlichen Gemeinschaft", HStR, vol. 1, 2 ed., 1995, pp. 815 e ss.; a partir deste ponto de partida e em relação com a comunidade internacional, Kotzur, M., Theorieelemente des Internationalen Menschenrechtsschutzes, 2001, pp. 217 e ss.

${ }^{38}$ Cfr. Tomuschat, Ch., "Die Internationale Gemeinschaft", Archiv des Völkerrechts, vol. 33, 1995, pp. 1 e ss.;

Walter, Ch., "Die Folgen der Globalisierung für die Europäische Verfassungsdiskussion", Deutsches Verwaltungsblatt, 2000, pp. 1 e ss., 7, fala da transformação do Estado nacional soberano em Estado membro limitado. Junto às vinculações dos direitos humanos já assinaladas, desempenham um importante papel as de caráter ambiental. Veja-se, por exemplo, Haedrich, M., "Internationaler Umweltschutz und Souveranitätsverzicht", Der Staat, vol. 29, 2000, pp. 547 e ss.

${ }^{39}$ Mößle, W., Regierungsfunktionen des Parlaments, 1986, p. 6.
} 
necessário que o poder soberano se des-concentre novamente. Os critérios são o "exercício cooperativo da soberania" e o princípio da subsidiariedade como "condição da realização da soberania" ${ }^{, 70}$. As unidades de decisão subsidiárias e parcialmente soberanas fundam-se numa unidade de ação da qual derivam, e não somente para a Europa, conteúdo, forma e Constituição ${ }^{40}$. Um conceito de soberania que seja igualmente válido tanto para a doutrina do direito constitucional como para o direito internacional já pressupõe este elemento cooperativo. O poder público, que atualmente tanto é exercido por unidades estatais como por unidades supraestatais surgidas dos processos de integração, não pode ser explicado por meio das categorias unidimensionais de uma teoria do Estado positivista, mas que deve ser extraído a partir da realidade do mundo globalizado dos Estados ${ }^{41}$. Os textos das constituições nacionais fazem neste sentido uma contribuição indispensável. Em seu preâmbulo e em seus artigos 23,24 e $25^{\text {N.T.7. }}$, aponta a Lei Fundamental de Bonn, como agudamente o tem assinalado Konrad Hesse, "para

\footnotetext{
${ }^{40} \mathrm{Na}$ "era fundacional” das Comunidades Européias falará Thieme, W., "Das Grundgesetz und die Öffentliche Gewalt Internationaler Staatengemeinschaftern”, VVDStRL, vol. 18, 1960, pp. 50 e ss., 55, de uma "amálgama parcial da soberania dos Estados, parte através da criação da Comunidade". Para o Estado constitucional cooperativo na atual etapa de desenvolvimento parece mais apropriada a imagem de uma "fusão" de competências de decisões soberanas parciais. Veja-se a respeito, Häberle, P., "Das Grundgesetz als Teilverfassung im Kontext der Eu/EG - Eine Problemskisse", FS H. Schiedermair, 2001, pp. 81 e ss., 82 e ss.; veja-se do mesmo autor "Europa - Eine Verfassungsgemeinschaft", em seu livro Europäische Verfassunglehre in Einzelstudiem, 1999, pp. 84 e ss., 100 e ss.

${ }^{41}$ Neste sentido, a "conclusão da teoria da ciência" em Kaiser, J. H., "Bewahrung und Veränderung Demokratischer und Rechtsstaatlicher Verfassungsstruktur in den Internationalen Gemeinschaften", VVDStRL, vol. 23, 1966, pp. 1 e ss., 26. N.T.7

"Preâmbulo - Consciente de sua responsabilidade perante Deus e os homens, animado pela vontade de defender sua unidade nacional e política e de servir para a paz do mundo, integrado numa Europa unida sobre a base da igualdade de direitos, o povo alemão dos Estados Federais de Baden, Bremen, Hamburgo, Hesse, Baixa Saxônia, Renânia do NorteWestfália, Renânia-Palatinado, Schleswig-Holstein, Wurttemberg-Baden e WurttembergHohenzollen, com o propósito de dar um novo ordenamento à vida política durante um período de transição, em virtude de seu poder constituinte, acordou a presente Lei Fundamental da República Federal da Alemanha, atuando, também, em nome daqueles alemães a quem estava vedada a colaboração, e mantendo de pé o convite para que todo povo alemão, em livre autodeterminação, consume a unidade e a liberdade da Alemanha. Artigo 23 - A presente Lei Fundamental vige desde agora no território dos Estados de Baden, Baviera, Bremen, Grande Berlin, Hamburgo, Hesse, Baixa-Saxônia, Renânia do Norte-Westfália, Renânia-Palatinado, Schleswig-Holstein, Wurttemberg-Baden e Wurttemberg-Hohenzollern. Em outras partes da Alemanha entrará em vigor depois da respectiva adesão. Artigo $24-1$. A Federação poderá transferir direitos de soberania, mediante lei, a instituições internacionais. 2. A Federação poderá incorporar-se, para a defesa da paz, a um sistema de segurança coletiva recíproca, admitindo para isso aquelas restrições de seus direitos soberanos que promovam e assegurem uma ordem pacífica e duradoura na Europa e entre os povos do mundo. 3. Para a solução de controvérsias internacionais a Federação aderirá a Convenções sobre arbitragem internacional, geral, amplo e obrigatório. Artigo 25 - As normas gerais do Direito Internacional Público são partes integrantes do direito federal. Estas normas têm primazia sobre as leis e constituem fontes diretas de direitos e obrigações para os habitantes do território federal."
} 
Tsatsos, D. Th., "Die Europäisches Uniongrundordnung im Schatten der Effektivitätsdiskussion”, EuGRZ 2000, pp. 517 e ss., 520; veja-se também Hailbronner, K., "Aufgabe von Souveränitätsrechten als EU-Mitglied - Deutsche Erfahrungen", FS H. Maurer, 2001, pp. 97 e ss., 103.

além de si mesma" "73. Novos propósitos terminológicos substituem a "supremacia absoluta" como característica da soberania. A interação de competências relativas, a "soberania compartilhada",74, o "poder da organização internacional", ou o "poder da integração supranacional",75, constituem outras tantas palavras-chave. Em última instância, a imagem corrente da "superposição" do direito internacional ou o europeu à soberania não é exato. Não é que uma esfera soberana se superponha à outra, mas sim que os diversos âmbitos de competências e os espaços soberanos se coordenam entre si e se vinculam através de um mecanismo de entrosamento de um com o outro. $\mathrm{O}$ cânon normativo típico, que manifesta a decisão do Estado Constitucional a favor da cooperação internacional, estrutura a soberania muito mais do que a desarticula. A relativização da soberania não leva a lhe dizer adeus, mas à sua reinterpretação como garantia estrutural.

\section{Perspectivas e Conclusão}

O poder soberano de configuração e a roupagem jurídica da qual se veste são dirigidos pela realidade da formação de comunidades políticas; portanto, estão condicionados historicamente. A discussão sobre a soberania é filha de sua respectiva época, mas não deve ser vítima do espírito da época, como tampouco daqueles que pretendam convertê-la em mito da unidade homogênea. O fato de que a abertura cooperativa do Estado constitucional tenha avançado mais na Europa do que na América Latina, e inversamente, que aí, como nos Estados Unidos, a comunidade política esteja concebida de maneira menos excludente com referência ao Estado que na Europa continental, somente pode enriquecer o diálogo cultural transatlântico. Havendo disposição recíproca à aprendizagem e à recepção, pode ser de muita ajuda assegurar a soberania daquilo que é importante em qualquer ordem constitucional: a "soberania do ser humano, que encontra sua expressão política na soberania do cidadão". 76

\section{Tradução: Marcus Vinícius Xavier de Oliveira* e Gabriel Gualano de Godoy*}

73

Hesse, K., Grundzüge des Verfassungsrechts der Bundesrepublik Deutschland, 20 ed., 1995 (reimp. 1999), n.m. 11. 


\section{Quaestio Iuris}

Pernice, I., "Europäisches Verfassunrecht im Werden”, em Bauer, H. et all. (eds.), Ius Publicum im Umbruch, 2000, pp. 25 e ss., 37.75

Assim Hobe, S., "Der Kooperationsoffene Verfassungsstaat”, Der Staat, vol. 37, 1998, pp. 521 e ss., 545. 76

Havel, V., "Die Herrchaft der Gesetze”, em ibidem, Sommermeditationen, 2 ed., 1994, pp. 14 e ss., 27.

Professor efetivo da Universidade Federal de Rondônia nas disciplinas Teoria do Estado e Direito Internacional no curso de Direito. Bacharel em Direito pela Universidade Federal de Rondônia. Especialista em Direito Público.

Revista e corrigida em setembro de 2012. (avaliar alterar essa data) 


\section{Quaestio Iuris}

Mestre em Direito das Relações Internacionais pela Universidade Federal de Santa Catarina. Doutorando em Direito pela Universidade do Estado do Rio de Janeiro. E-mail advmarcusvinicius@ gmail.com

Oficial de Proteção do Alto Comissariado das Nações Unidas para Refugiados - ACNUR/Brasil. Bacharel em

Direito pela Universidade Federal do Paraná. Mestre em Direito pela Universidade Federal do Paraná. Mestre em Direito, Antropologia e Sociedade pela London School of Economics and Political Science. Doutorando em Direito pela Universidade do Estado do Rio de Janeiro. E-mail gabrielgualano@ gmail.com 